\title{
An association between anti-platelet drug use and reduced cancer prevalence in diabetic patients: results from the Vermont Diabetes Information System Study
}

\author{
Chris E Holmes*1, Maria E Ramos-Nino² and Benjamin Littenberg ${ }^{3}$
}

\begin{abstract}
Background: Diabetes is associated with an increased risk of several malignancies. Both diabetic patients and patients with cancer have an increase in platelet reactivity and platelet activation has recently emerged as a potential mediator of cancer progression. Drug therapies, such as aspirin, that reduce platelet reactivity reduce both cardiovascular and cancer risk.

Methods: We performed a cross-sectional analysis to assess the association between history of cancer and current anti-platelet drug use in a primary care population of adults with diabetes enrolled in the Vermont Diabetes Information System.

Results: Self-reported characteristics, medical history, and a complete medication list were recorded on 1007 diabetic adults. Fifty percent of diabetic patients used an anti-platelet drug. In unadjusted analysis, no association was seen between anti-platelet drug use and cancer history $(\mathrm{OR}=0.93 ; P=.70)$. Platelet inhibitor use was associated with a decreased patient-reported history of malignancy in a multivariate logistic regression adjusted for age, sex, body mass index, comorbidity, and number of medications ( $\mathrm{OR}=0.66 ; \mathrm{Cl} 0.44-0.99 ; P=.045)$. Similar odds of association were seen in both males and females, and for aspirin and non-aspirin platelet inhibitor therapy.

Conclusions: Our data suggest an association between anti-platelet drug use and reduced cancer prevalence in patients with diabetes. Given the potentially large implications of our observations in the diabetic population, further studies are required to determine if this association is causal.
\end{abstract}

\section{Background}

Epidemiologic studies have found an increase in cancer mortality and risk of several cancer types in persons with type 2 diabetes mellitus[1-4]. The association is likely multifactorial and may be mediated by insulin resistance and the metabolic syndrome as well as common life-style choices and obesity[5,6]. Patients with diabetes commonly display an increase in platelet reactivity [7], and large studies have suggested they derive particular cardiovascular benefit from platelet inhibition [8]. Accumulating evidence also suggests a role for platelet activation in cancer progression and an increase in platelet reactiv-

*Correspondence: ceholmes@uvm.edu

1 Hematology and Oncology, University of Vermont, Given Building Second Floor, Burlington, VT 05401, USA

Full list of author information is available at the end of the article ity has been seen in patients with metastatic cancer [911].

The use of aspirin, an inhibitor of platelet reactivity, is associated with cancer prevention in two of the most common solid tumor malignancies affecting patients with diabetes: colorectal and breast cancer. The efficacy of aspirin in cancer prevention has been linked in part to inhibition of COX-2 (inducible) driven pathways of malignancy development (reviewed in [12]). In murine models, however, thrombocytopenia and platelet antagonists decrease tumor metastases indirectly supporting a plausible role for COX-1 platelet inhibition in cancer prevention and treatment $[13,14]$.

Given the role of aspirin in cancer prevention in the general population, the increase in platelet reactivity in 
diabetics, and the emerging role of platelet activity in cancer progression, we explored the association between anti-platelet drug use and cancer history in persons with type 2 diabetes. We hypothesized that persons with type 2 diabetes taking anti-platelet drugs such as aspirin would have a decreased risk of cancer compared to diabetic persons not using aspirin.

\section{Methods}

The Vermont Diabetes Information System was a randomized trial of a decision support system in diabetes [15]. All diabetic adults in 69 primary care practices in Vermont and adjacent New York were enrolled. Following ascertainment of informed consent, a randomly selected subset of 1007 subjects completed a survey and a home visit by trained researchers between July 2003 and March 2005. Patients were asked to gather all current mediations, including over the counter drugs. Staff recorded the drug name, dose, frequency, and route of administration from each container. Duration of therapy was not ascertained. Weight and height were recorded using a portable stadiometer and scale.

Patient characteristics were obtained by questionnaire. Comorbidity (in addition to diabetes) was determined using a modification of the Self-Administered Comorbidity Questionnaire [16]. Patients who reported a history of any malignancy, including leukemia or lymphoma, were classified as having cancer. Dates of diagnosis, treatments, and site were not recorded. A1C was measured using high performance liquid chromatography or a Bayer DCA 2000 immunoassay point of care instrument (less than 1\% of tests). Anti-platelet drug use was defined as daily use of aspirin (at least $75 \mathrm{mg}$ ), clopidogrel, ticlopidine, or cilostazol or a combination of these medications. The specific indication for anti-platelet therapy was not recorded.

We performed a cross-sectional association analysis of the interviewed subjects at the time of their enrollment in the VDIS trial. We explored the association between cancer and the use of anti-platelet agents, using logistic regression with history of cancer as the outcome variable and the use of anti-platelet drugs as the primary predictor variable. We then adjusted for possible confounding by social and clinical factors. Potential confounders tested were: gender, age, race (white/other), glycosylated hemoglobin level (A1C;mg\%), insulin use (yes/no), body mass index $\left(\mathrm{BMI} ; \mathrm{kg} / \mathrm{m}^{2}\right)$, alcohol drinking (yes/no), cigarette smoking (yes/no), income (in eight ordered categories), duration of diabetes in years, high comorbidity (two or more comorbid conditions, number of medications, physical function status and mental function status. To reduce the number of variables in the final model, we excluded potential confounders that were associated with the outcome in univariate analysis with $\mathrm{P}>0.2$. The final multivariate analysis adjusted for age, sex, body mass index, presence of multiple co-morbidities and number of medications. In secondary analyses, we studied selected subgroups of patients based on sex and use of different platelet inhibitors. Association was expressed as the odds ratio (OR) with 95\% confidence interval (CI).

All research was carried out according to the Helsinki declaration per the University of Vermont Institutional Review Board.

\section{Results}

Selected characteristics of the study population $(1,007$ subjects) based on anti-platelet drug users versus nonusers are described in Table 1 . Half of the population were seniors, two thirds were obese, and $48 \%$ had an A1C $>7 \%$. There was little racial diversity, reflecting the local population. Thirteen percent of patients reported a history of malignancy. Half of the patients used a platelet inhibitor (aspirin or non-aspirin platelet inhibitor). Aspirin use in this population has previously been found to be more prevalent in subjects with coronary artery disease and in men [17].

In unadjusted analysis, no significant association was seen between anti-platelet drug use and cancer history $(\mathrm{OR}=0.93 ; \mathrm{CI}=(0.64,1.34) ; P=.70)$, Table 1 . However, an unadjusted analysis revealed a significant association between cancer history and age, more than one comorbid condition, BMI and number of prescriptions medications $(\mathrm{p} \leq 0.05)$. In this same analysis, sex, ethnicity, use of insulin therapy, hemoglobin $\mathrm{A} 1 \mathrm{C}$, alcohol use, median income, duration of diabetes, number of anti-diabetic medications and physical functional status were not associated with a diagnosis of cancer.

A multivariate analysis adjusting for confounding variables revealed significantly lower odds of a cancer history among anti-platelet drug users $(\mathrm{OR}=0.66$; CI 0.44-0.99, Table 2). Because aspirin use was more common in men and some cancers are sex-associated, we repeated the analyses for each sex. The magnitude of the association was maintained in both males and females; however, the confidence intervals broadened with the smaller sample size. The association between anti-platelet drug use and reduced cancer history was not maintained in persons under the age of 65 years but was of significance in persons over the age of 65 years $(P=0.047)$.

The individual anti-platelet drugs studied have distinct characteristics. For instance, aspirin inhibits platelets and inhibits COX pathways in tissues and tumors but the others do not. To exclude the possibility that the apparent protective effect of these medications is due to a medication-specific characteristic (other than anti-platelet activity), we divided the treatments into two groups (aspirin and non-aspirin platelet inhibitors) and repeated the analysis excluding any subjects who used one or the other 
Table 1: Characteristics of 1007 study subjects

\begin{tabular}{|c|c|c|c|c|c|c|c|}
\hline & $n$ & Mean & Range & $n$ & Mean & Range & $P$ \\
\hline Anti-platelet therapy & & Absent & \multicolumn{5}{|c|}{ Present } \\
\hline Age in years & 499 & 62.1 & $22.2-89.5$ & 508 & 67.6 & $36.0-92.6$ & $<.001$ \\
\hline Gender: male & 499 & $39.7 \%$ & & 508 & $51.6 \%$ & & $<.001$ \\
\hline Race: white, & 497 & $96.6 \%$ & & 507 & $98.0 \%$ & & .15 \\
\hline Body mass index in $\mathrm{kg} / \mathrm{m}^{2}$ & 492 & 34.5 & $16.1-64.6$ & 502 & 33.1 & $15.8-68.0$ & .003 \\
\hline Glycosylated hemoglobin A1C & 497 & $7.1 \%$ & $4.0-13.5$ & 506 & $7.1 \%$ & $4.9-12.9$ & .85 \\
\hline More than 1 comorbid condition & 499 & $45.1 \%$ & & 508 & $53.5 \%$ & & .007 \\
\hline Current smoker & 498 & $18.5 \%$ & & 508 & $15.4 \%$ & & .19 \\
\hline Number of medications & 499 & 7.7 & $0-29$ & 508 & 9.8 & $1-29$ & $<.001$ \\
\hline Self-reported history of malignancy & 499 & $13.0 \%$ & & 508 & $12.2 \%$ & & .70 \\
\hline History of cancer & \multicolumn{3}{|c|}{ Absent } & \multicolumn{3}{|c|}{ Present } & \\
\hline Age in years & 880 & 65.2 & $22.2-91.7$ & 127 & 69.1 & $34.5-92.6$ & $<.001$ \\
\hline Gender: male & 880 & $46.2 \%$ & & 127 & $41.7 \%$ & & .34 \\
\hline Race: white, & 878 & $97.3 \%$ & & 126 & $97.6 \%$ & & .82 \\
\hline Body mass index in $\mathrm{kg} / \mathrm{m}^{2}$ & 868 & 34.0 & $15.8-68.0$ & 126 & 32.6 & $19.7-53.8$ & .05 \\
\hline Glycosylated hemoglobin A1C & 876 & $7.1 \%$ & $4.0-13.5$ & 127 & $7.0 \%$ & $4.8-13.3$ & .13 \\
\hline More than 1 comorbid condition & 880 & $46.2 \%$ & & 127 & 71.7 & & $<.001$ \\
\hline Current smoker & 879 & $17.8 \%$ & & 127 & $11.0 \%$ & & .06 \\
\hline Number of medications & 880 & 8.6 & $0-29$ & 127 & 9.9 & $0-29$ & .003 \\
\hline Anti-platelet therapy & 880 & $50.7 \%$ & & 127 & $48.8 \%$ & & .70 \\
\hline
\end{tabular}

of the groups (Table 2). Although the smaller sample sizes again reduced precision, the odds ratios changed little, indicating that the association is not due to some specific characteristic of one group of platelet inhibitor.

\section{Discussion}

Platelet inhibitors were significantly associated with reduced odds of a cancer history in adults with diabetes in our study population. The association was not due to confounding by age, sex, obesity, or number of medications or co-morbidities. The odds of association were similar in men and women and for both aspirin and nonaspirin platelet inhibitor users although smaller numbers broadened the observed confidence intervals. Our original hypothesis was based on data from multiple studies supporting the use of aspirin therapy in cancer prevention in selected populations. We chose to focus on patients with diabetes because they have an increased reported cancer risk, an increase in platelet reactivity and a clear benefit from anti-platelet therapy in the cardiovascular setting. Consistent with our hypothesis, we found a reduction in reported cancer history was associated with anti-platelet drug use in a community based diabetic population.
The strong association between platelet inhibitors and a history of cancer is apparent only when controlling for other factors such as age, sex, obesity, and burden of comorbid conditions. This demonstrates that one or more of these factors confounds the relationship between platelet inhibition and cancer. As in all non-experimental studies, the possibility of additional, unmeasured, confounders that further influence the relationship between platelet inhibition and cancer cannot be excluded. Additionally, our population was heterogeneous with regards to cancer type and larger studies and/or cancer specific studies will be needed to determine an association (if any) between specific cancer subtypes and aspirin use in patients with diabetes.

These results are consistent with prior studies in selected patient populations. For example, aspirin use prevents the development of colorectal adenomas in patients with a prior history of these lesions [18]. In addition, several studies have suggested that aspirin use is associated with a reduced risk of breast cancer[19,20]. However, not all studies of aspirin have demonstrated a benefit in cancer prevention [21]. Our results are the first to focus on a diabetic population. 
Table 2: Association between platelet inhibitor therapy and history of cancer

\begin{tabular}{|c|c|c|c|c|}
\hline \multirow[t]{2}{*}{ Population } & \multicolumn{4}{|c|}{ Multivariate (Adjusted) Analyses* } \\
\hline & $N$ & OR & $(95 \% \mathrm{Cl})$ & $P$ \\
\hline All subjects & 994 & 0.66 & $(0.44,0.99)$ & .045 \\
\hline Women & 540 & 0.63 & $(0.36,1.08)$ & .09 \\
\hline Men & 454 & 0.71 & $(0.38,1.32)$ & .29 \\
\hline Age $<65$ years & 477 & 0.93 & $(0.46,1.90)$ & .85 \\
\hline Age 65 years or more & 530 & 0.61 & $(0.37,0.99)$ & .047 \\
\hline Excluding users of non-aspirin inhibitors & 925 & 0.67 & $(0.44,1.03)$ & .07 \\
\hline Excluding users of aspirin & 525 & 0.64 & $(0.22,1.80)$ & .39 \\
\hline
\end{tabular}

${ }^{*}$ Adjusted for age, sex, body mass index, presence of $\geq 2$ co-morbidities, and number of medications. Body mass index was not available for 13 subjects who were excluded from the multivariate analyses.

We found no difference in our study between male and female users of platelet inhibitor therapy. This is consistent with the finding that men and women have similar reductions in platelet reactivity to low dose aspirin therapy [22]. In addition, reductions in cancer risk associated with aspirin therapy are seen in gender specific cancers such as prostate cancer and breast cancer $[20,23]$.

Mechanisms that explain the possible association between anti-platelet therapy and cancer were not addressed by this study. Although aspirin has COX- and prostaglandin-mediated tissue effects, the other agents studied do not, suggesting the effects might be related to platelet inhibition. In the laboratory, ticlopidine (one of two non-aspirin platelet inhibits used in our patient population) has been reported to inhibit pulmonary metastasis of melanoma as well as metastasis in a Lewis lung carcinoma model [24]. No human studies using these agents to prevent or treat cancer have been reported. Interestingly, some inhibitors of platelet function such as glycoprotein IIB-IIIA inhibitors have anti-tumor activity in animal models and have been found to have greater platelet inhibitor activity in patients with diabetes than non-diabetic patients [25].

This study provides the first evidence to suggest antiplatelet therapy may have an anti-cancer benefit in patients with diabetes. However, the conclusions are limited by the cross-sectional design, racial homogeneity of the subjects, use of unconfirmed cancer diagnoses, and lack of data on cancer site. In addition, anti-platelet drug duration or dose of therapy was not available and the temporal relationship between medication use and cancer diagnosis is unknown. While the majority of patients in our study are anticipated to have Type II diabetes, we did not collect this data directly and; therefore, were unable to determine if the demonstrated association is the same for both type I and type II diabetics.

\section{Conclusions}

We found anti-platelet drug use was associated with a reduced number of reported cancer diagnoses in adults with diabetes who participated in the Vermont Diabetes Information System Study. Our results suggest targeting patient populations with increased platelet activation, such as patients with diabetes mellitus, may be a useful strategy to move platelet inhibitors successfully into the cancer prevention or treatment setting. Our results will need confirmation in larger, prospective studies given the cross-sectional design of the study. If confirmed, our results suggest patients with diabetes may receive a dual health benefit from a single, inexpensive drug.

\section{Abbreviations}

COX: cyclo-oxygenase; VDIS: Vermont Diabetes Information System; A1C: glycosylated hemoglobin level; $\mathrm{Cl}$ : confidence interval; OR: odds ration

\section{Competing interests}

The authors, $\mathrm{CH}$ and MR, declare that they have no competing interests. $\mathrm{BL}$ is an officer and shareholder of Vermedx, Inc., which distributes the Vermont Diabetes Information System.

\section{Authors' contributions}

$\mathrm{CH}$ conceived the study hypothesis, participated in data and study analysis and interpretation; MR aided in data analysis; BL established the VDIS study, performed data analysis and participated in study analysis and interpretation. All authors read and approved the final manuscript.

\section{Author Details}

${ }^{1}$ Hematology and Oncology, University of Vermont, Given Building Second Floor, Burlington, VT 05401, USA, 2Department of Pathology, University of Vermont, Burlington, VT 05405, USA and 3University of Vermont, 89 Beaumont Avenue, S459, Burlington, VT 05405, USA

Received: 26 November 2009 Accepted: 15 June 2010

Published: 15 June 2010

\section{References}

1. Larsson SC, Orsini N, Wolk A: Diabetes mellitus and risk of colorectal cancer: a meta-analysis. J Natl Cancer Inst 2005, 97(22):1679-1687.

2. Friberg E, Mantzoros CS, Wolk A: Diabetes and risk of endometrial cancer: a population-based prospective cohort study. Cancer Epidemiol Biomarkers Prev 2007, 16(2):276-280. 
3. Wideroff L, Gridley G, Mellemkjaer L, Chow WH, Linet M, Keehn S, BorchJohnsen $\mathrm{K}$, Olsen $\mathrm{JH}$ : Cancer incidence in a population-based cohort of patients hospitalized with diabetes mellitus in Denmark. J Nat/ Cancer Inst 1997, 89(18):1360-1365.

4. Coughlin SS, Calle EE, Teras LR, Petrelli J, Thun MJ: Diabetes mellitus as a predictor of cancer mortality in a large cohort of US adults. Am J Epidemiol 2004, 159(12):1160-1167.

5. Giovannucci E: Diet, body weight, and colorectal cancer: a summary of the epidemiologic evidence. Journal of women's health (2002) 2003, 12(2):173-182.

6. Giovannucci E: Nutrition, insulin, insulin-like growth factors and cancer. Hormone and metabolic research = Hormon- und Stoffwechselforschung = Hormones et metabolisme 2003, 35(11-12):694-704.

7. Sobel BE, Schneider DJ: Platelet function, coagulopathy, and impaired fibrinolysis in diabetes. Cardio/ Clin 2004, 22(4):511-526.

8. Final report on the aspirin component of the ongoing Physicians' Health Study. Steering Committee of the Physicians' Health Study Research Group. N Engl J Med 1989, 321(3):129-135.

9. Nash GF, Turner LF, Scully MF, Kakkar AK: Platelets and cancer. Lancet Oncol 2002, 3(7):425-430.

10. Sierko E, Wojtukiewicz MZ: Platelets and angiogenesis in malignancy. Semin Thromb Hemost 2004, 30(1):95-108.

11. Jurasz $P$, North $S$, Venner $P$, Radomski MW: Matrix metalloproteinase-2 contributes to increased platelet reactivity in patients with metastatic prostate cancer: a preliminary study. Thromb Res 2003, 112(1-2):59-64.

12. Thun MJ, Henley SJ, Patrono C: Nonsteroidal anti-inflammatory drugs as anticancer agents: mechanistic, pharmacologic, and clinical issues. J Natl Cancer Inst 2002, 94(4):252-266.

13. Gasic GJ, Gasic TB, Stewart CC: Antimetastatic effects associated with platelet reduction. Proc Natl Acad Sci USA 1968, 61(1):46-52.

14. Nierodzik ML, Klepfish A, Karpatkin S: Role of platelets, thrombin, integrin Ilb-IIla, fibronectin and von Willebrand factor on tumor adhesion in vitro and metastasis in vivo. Thromb Haemost 1995 74(1):282-290

15. MacLean CD, Littenberg B, Gagnon M, Reardon M, Turner PD, Jordan C: The Vermont Diabetes Information System (VDIS): study design and subject recruitment for a cluster randomized trial of a decision support system in a regional sample of primary care practices. Clin Trials 2004, 1(6):532-544

16. Sangha O, Stucki G, Liang MH, Fossel AH, Katz JN: The Self-Administered Comorbidity Questionnaire: a new method to assess comorbidity for clinical and health services research. Arthritis Rheum 2003, 49(2):156-163.

17. Miller SR, Littenberg B, MacLean CD: Prevalence of antiplatelet therapy in patients with diabetes. Cardiovasc Diabetol 2005, 4:18.

18. Cole BF, Logan RF, Halabi S, Benamouzig R, Sandler RS, Grainge MJ, Chaussade S, Baron JA: Aspirin for the chemoprevention of colorectal adenomas: meta-analysis of the randomized trials. J Natl Cancer Inst 2009, 101(4):256-266

19. Harris RE, Chlebowski RT, Jackson RD, Frid DJ, Ascenseo JL, Anderson G, Loar A, Rodabough RJ, White E, McTiernan A: Breast cancer and nonsteroidal anti-inflammatory drugs: prospective results from the Women's Health Initiative. Cancer Res 2003, 63(18):6096-6101.

20. Takkouche B, Regueira-Mendez C, Etminan M: Breast cancer and use of nonsteroidal anti-inflammatory drugs: a meta-analysis. J Nat/ Cancer Inst 2008, 100(20):1439-1447.

21. Eliassen AH, Chen WY, Spiegelman D, Willett WC, Hunter DJ, Hankinson SE: Use of aspirin, other nonsteroidal anti-inflammatory drugs, and acetaminophen and risk of breast cancer among premenopausal women in the Nurses' Health Study II. Arch Intern Med 2009, 169(2):115-121. discussion 121

22. Becker DM, Segal J, Vaidya D, Yanek LR, Herrera-Galeano JE, Bray PF, Moy TF, Becker LC, Faraday N: Sex differences in platelet reactivity and response to low-dose aspirin therapy. Jama 2006, 295(12):1420-1427.

23. Jacobs EJ, Rodriguez C, Mondul AM, Connell CJ, Henley SJ, Calle EE, Thun $\mathrm{MJ}$ : A large cohort study of aspirin and other nonsteroidal antiinflammatory drugs and prostate cancer incidence. J Nat/ Cancer Inst 2005, 97(13):975-980.

24. Kohga S, Kinjo M, Tanaka K, Ogawa H, Ishihara M, Tanaka N: Effects of 5-(2 chlorobenzyl)-4,5,6,7-tetrahydrothieno[3,2-c]pyridine hydrochloride (Ticlopidine), a platelet aggregation inhibitor, on blood-borne metastasis. Cancer Res 1981, 41(11 Pt 1):4710-4714.
25. Razmara M, Hjemdahl P, Ostenson CG, Li N: Platelet hyperprocoagulant activity in Type 2 diabetes mellitus: attenuation by glycoprotein Ilb/IIla inhibition. J Thromb Haemost 2008, 6(12):2186-2192.

\section{Pre-publication history}

The pre-publication history for this paper can be accessed here: http://www.biomedcentral.com/1471-2407/10/289/prepub

doi: $10.1186 / 1471-2407-10-289$

Cite this article as: Holmes et al., An association between anti-platelet drug use and reduced cancer prevalence in diabetic patients: results from the Vermont Diabetes Information System Study BMC Cancer 2010, 10:289

\section{Submit your next manuscript to BioMed Central and take full advantage of:}

- Convenient online submission

- Thorough peer review

- No space constraints or color figure charges

- Immediate publication on acceptance

- Inclusion in PubMed, CAS, Scopus and Google Scholar

- Research which is freely available for redistribution

Submit your manuscript at www.biomedcentral.com/submit
C Biomed Central 